\title{
Ultimi raggi
}

Ultimi raggi

di velato tramonto

illuminano

il volto morto

di Gesù Cristo:

tutto è contuso.

La contrattura tetanica

dei muscoli facciali

ha sconvolto l'anatomia

del volto più bello.

Di questo solo figlio

di Dio portano via

il cadavere

e vanno al sepolcro.

Un boato di masso

che rotola e chiude

parla di fine

ed urla a nome

di chiunque ha sperato

la morte di un mito.

Solo l'amore di Lui

per gli uomini

aveva pensato alla Sua prova:

la mano onnipotente

sul volto freddo

del suo unico Cristo.

Per un attimo ho pensato che

Dio avesse perso la testa

lasciando in terra Cristo

linciato dai peccati.

Dr. med. Sergio Marengo, Orselina 